\title{
Routine check for plagiarism
}

\author{
Klaus Eichmann ${ }^{1}$
}

Received: 5 September 2015/Accepted: 5 September 2015/Published online: 24 September 2015

(C) Springer Basel 2015

This is to inform our authorship that since August 1, 2015 all incoming manuscripts routinely undergo a similarity check using the iThenticate CrossCheck service that has been integrated into Editorial Manager. The similarity check has been implemented so as to run in the background for each new submitted manuscript and each revised submission. Obviously, bibliographic references and quotations are excluded. Thus, upon first inspection of a new or revised manuscript, editors will automatically see a percentage figure indicating the sum of all text similarities with other published academic literature. If the percentage is alarmingly high, editors can assess a "match overview" consisting of a list of source materials together with the color highlighted matching text sections, each given with a percentage figure and the absolute number of identical words. Editors then have to take a value judgement: plagiary or not.

Text recycling and plagiarism are a growing concern in the academic community, and it is hoped that the new service will help to minimize this form of scientific misconduct. With several weeks of experience now I am happy to report that the vast majority of submitted manuscripts has been essentially unsuspicious of plagiarism. Nevertheless, a handful of cases with significant text similarities has been identified and returned to the authors mainly or partially for this reason. In the majority of these cases, authors had recycled parts of their own published papers, likely just for convenience and without being conscious of having committed a scientific misconduct.

Several arguments are frequently put forward to justify text identities in natural science literature, and are mostly

Klaus Eichmann

eichmann@immunbio.mpg.de

1 Max-Planck-Institute of Immunobiology and Epigenetics, Freiburg, Germany used to play down redundancies with ones own previous publications. For example, authors have claimed that what is important in a scientific paper are the experimental data, while the text is of secondary or of minor relevance. Others insist that certain phrases for describing a scientific context are simply ideal and cannot be improved. This point is primarily but not exclusively made when it comes to describing materials and methods.

I do not accept these arguments. Essential requirements of scientific publications are novelty and progress in knowledge. Novelty and progress are intimately connected with new original and conceptual thinking. Language and writing are our means to express our thoughts and new thoughts require new wording and writing. Redundant writing means redundant thinking, no matter weather a procedure or a hypothesis are described. Methods that are utilized essentially as described need not be described again, they can be cited.

Fortunately, rarely encountered are manuscripts that in parts are a patchwork of text sections copied from one or several source materials written by different authors. This is more difficult to play down, and I do not think that authors using such approaches have the possibility to invent any personal justification of their conduct. In other words, authors using such techniques must be conscious of their own scientific misconduct, with all the consequences for self-respect they must experience. Through CMLS, manuscripts of this type will have no chance to enter the academic literature in the future.

CMLS editors are confident that CMLS authors will appreciate and welcome our new routine, as a sure means to ban plagiarism and to ensure originality and novelty of scientific publication.

Klaus Eichmann

Editor-in-Chief 